University of Rhode Island

DigitalCommons@URI

Open Access Master's Theses

1990

\title{
A Measurement Model for Relapse Ideaology
}

Jeffery Mark Bellis

University of Rhode Island

Follow this and additional works at: https://digitalcommons.uri.edu/theses

\section{Recommended Citation}

Bellis, Jeffery Mark, "A Measurement Model for Relapse Ideaology" (1990). Open Access Master's Theses. Paper 1700.

https://digitalcommons.uri.edu/theses/1700

This Thesis is brought to you for free and open access by DigitalCommons@URI. It has been accepted for inclusion in Open Access Master's Theses by an authorized administrator of DigitalCommons@URI. For more information, please contact digitalcommons-group@uri.edu. 
A MEASUREMENT MODEL FOR

RELAPSE IDEOLOGY

BY

JEFFREY MARK BELLIS

A THESIS SUBMITTED IN PARTIAL FULFILIMENT OF THE REQUIREMENTS FOR THE DEGREE OF

MASTER OF ARTS

IN

PSYCHOLOGY

UNIVERSITY OF RHODE ISLAND

1990

$2 \times 78367$ 
Abstract

A 12-item Relapse Ideology questionnaire was developed to measure attitudes and beliefs of smokers and ex-smokers ( $\underline{N}$ =651) towards relapse. Three ideological orientations were constructed, based on the disease, moral and addictive behavior models of addiction described by Marlatt and Gordon (1985). The structure of the questionnaire was examined using principal components analysis and structural modeling techniques. Results suggested a correlated, three factor solution which corresponded to the three models of addiction. The three factor solution was replicated across samples of men and women, samples from Rhode Island and Texas, and across the total sample over time ( 6 months). Internal consistencies for the three scales ranged from .73 to .85 . The three relapse ideology scales were able to successfully discriminate between light and heavy smokers, and were found to be related to movement through the stages of change (Prochaska \& Diclemente, 1983). 
Acknowledgement

Many thanks to Joe Rossi for his guidance and support throughout the completion of this project. 
Table of contents

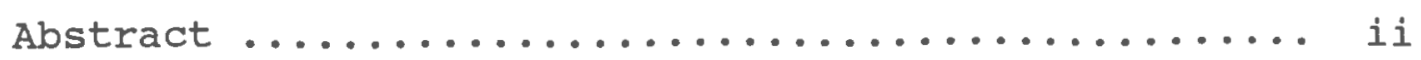

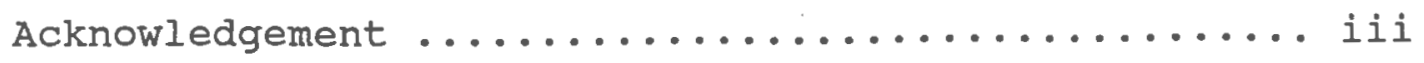

List of Tables ........................... v

List of Figures ......................... vi

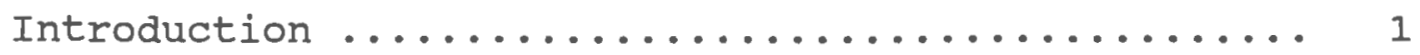

Method .................................. 5

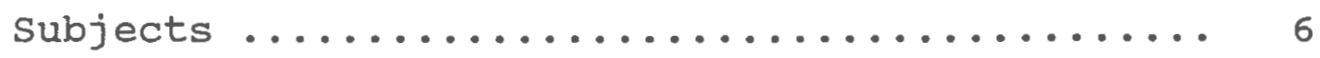

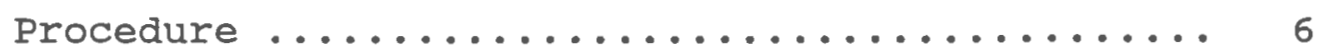

Results ................................. 7

Confirmation of Factor structure ........... 7

stability of Factor structure Across Samples ... 8

stability of Factor structure over Time ....... 11

Psychometric Properties .................. 11

External validity ...................... 12

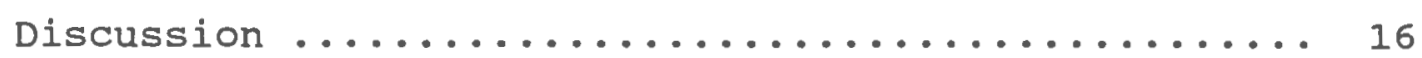

Future work .......................... 19

References ............................. 23

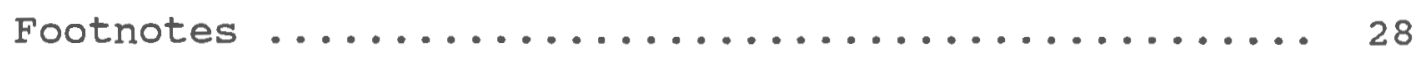

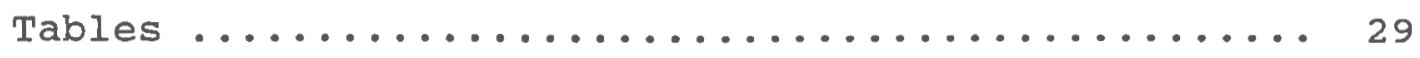

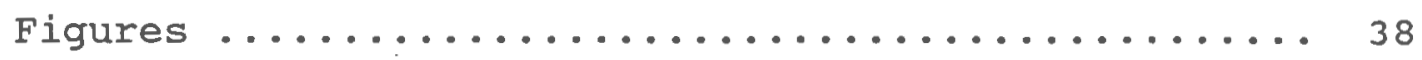

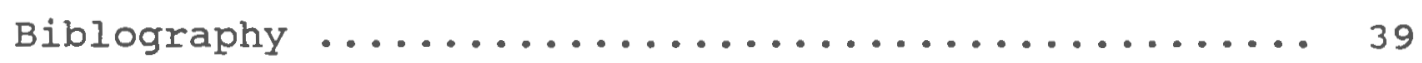


List of Tables

Table 1 Principal Component Loadings: 12 Item,

3 Factor solution Round 1

- Rhode Island Sample .................... 29

Table 2 comparison of Alternative structural Models

- Round 1 Texas Sample .................. 30

Table 3 Multiple Sample Analyses: Male and Female Samples - Rhode Island and Texas Samples ..... 31

Table 4 scale statistics and Correlations

- Round 1 Sample ....................... 32

Table 5 scale Correlations with social Desirability and Demographic Variables

- Round 1 and Round 2 samples .............. 33

Table 6 correlations with other smoking scales

- Round 1 Sample...................... 34

Table 7 Relapse Ideology scale Item Means and standard Deviations - Light and Heavy Smokers ....... 35

Table 8 Relapse Ideology scale Item Means and standard Deviations - Non-progressors vs. Progressors . . 36

Table 9 Standardized Discriminant Weights

- Non-progressors vs. Progressors Analysis ... 37 
List of Figures

Figure 1 Correlated Three-factor Model with Item Loadings and Item Error Variances ....... 38 
It is accepted that addiction treatment programs are generally effective in helping individuals with cessation of a problem behavior. However, clinicians have been much less successful with regard to preventing relapse after termination of a treatment program or effort. Studies indicate that approximately $75 \%$ of subjects completing addiction treatment programs relapse within one year of end of treatment (Hunt \& Belaspec, 1974). Traditionaliy, most treatment programs have focused on the initial cessation of the addictive behavior (e.g., substance use). However, more recently a recognition of the importance of the maintenance stage of behavior change, with an emphasis on the environmental, physiological, and situational precipitants of potential relapse, has emerged in the literature (Baer \& Lichtenstein, 1988; Brownell, Marlatt, et al., 1986; Marlatt \& Gordon, 1985; Prochaska \& Diclemente, 1983, 1986).

Several current models of relapse have emphasized the factors that antecede and follow relapse episodes (Baer, et.al, 1989; Brownell, Glynn, et.al, 1986; Niaura, et. al, 1988; Prochaska \& Diclemente, 1983, 1986). It is felt that one's beliefs regarding relapse may influence susceptibility not only to relapse but to other aspects of the behavior change process as well. Successful measurement of relapse ideology may constitute an important component of a client profile, and may be useful as an aid in either predicting 
success of treatment, or, more probably, suggesting an appropriate therapeutic mode for a given profile.

An initial step toward exploring the relationship between beliefs about relapse and behavior change is to develop a reliable means of measuring subjects' personal beliefs, or ideology, concerning the relapse process.

This study was designed to determine whether subjects participating in a large, naturalistic study of smoking behavior hold distinct, measurable viewpoints regarding the nature and significance of smoking relapse. These beliefs were assessed using a newly developed measure, the Relapse Ideology Questionnaire, designed to measure three latent constructs consistent with the moral, the disease, and the addictive behavior models of addiction presented by Marlatt and Gordon (1985).

The moral model suggests that addiction is based on lack of willpower, and that the "addict" lacks the character or "moral fiber" to resist temptation. The disease model holds that "addicts" cannot voluntarily control their substance abuse behavior, and that they are helpless in the face of irresistible physiologically based cravings and compulsions. Both views, addict as "sinner" and addict as "sick," are popular with large segments of society. Indeed, both have been dominant in the medical field at one time or another. The addictive behavior model describes addiction from a social-learning perspective, as overlearned "bad habits." This view suggests that addictive behaviors can be described 
and modified in accordance with general principles of learning, especially antecedents and consequences, just as any other habits might be.

Marlatt and Gordon's choice of these competing models is historically, as well as theoretically founded. Prior to and in the early part of this century, the moral model of addiction was predominant. Lacking a more sophisticated or technical explanation, individual differences were attributed solely to one's character. Early in this century, as greater understanding of physiology emerged, a less judgmental medical model was proposed and ultimately adopted by the medical community. Recent interest in the maintenance stage of behavior change and the challenge of relapse prevention has led to the development of an addictive behavior model. Though less widely accepted, this theoretical model has generated a great deal of research in recent years (Baer \& Lichtenstein, 1988; Brownell, Marlatt, et. al, 1986; Marlatt \& Gordon, 1985).

Theoretically these models may be differentiated with regard to the attribution of responsibility for development of the addictive behavior and for the cessation of the behavior, in a manner originally suggested by Brickman and his colleagues (1982). Brickman's four models of helping and coping are differentiated by attribution of responsibility for the development of a problem and for its solution. The moral model holds the individual responsible both for the cause of the problem (weakness), as well as for 
termination of the behavior (proper motivation). The medical model absolves the individual of responsibility for obtaining the problem (an illness), as well as for the cure (expert treatment). The compensatory model, however, does not hold the individual responsible for creating the problem, but it does place the responsibility for developing a solution on the individual. Lastly, the enlightenment model holds the individual responsible for the problem, but not for the solution. Brickman cites Alcoholics Anonymous as an example of an enlightenment model organization in that it holds members responsible for their past history of drinking, yet encourages them to recognize their inability to overcome their problem without the help of God and a community of sober alcoholics. Brickman concludes that the choice of models within the context of a helping or coping strategy has an important influence on the outcome of treatment or self-help efforts.

Marlatt and Gordon's (1985) three models of addiction, the moral model, the disease model (a medical model), and the addictive behavior model (a compensatory model), are consistent with Brickman's presentation with regard to attribution of responsibility. Marlatt and Gordon, however, do not include a model of addiction consistent with Brickman's enlightenment model. With regard to smoking cessation, exclusion of an enlightenment model seems appropriate in that there are no popular or professionally endorsed methods or organizations which follow this model in 
an effort to help individuals stop smoking. Perhaps few believe that the consequences of cigarette smoking are serious enough to require such drastic measures as calling upon a "higher power," or becoming a member of a highly structured self-help group. When considering other behavior problems, such as alcoholism or drug addiction, Marlatt and Gordon's exclusion of an enlightenment model may be an oversight in that ideologies suggested by Alcoholics Anonymous, or Narcotics Anonymous methods, for example, are not adequately explained by any of the three theoretical models of addiction they present.

This study involved the development of a questionnaire consisting of items designed to measure constructs related to the three previously described models of addiction. The scope of the project is circumscribed by a rigorous analysis of the measurement properties of the Relapse Ideology questionnaire.

\section{Method}

\section{Measure}

The Relapse Ideology questionnaire is composed of 22 items designed to differentiate subjects with regard to beliefs related to three theoretical models of addiction (Marlatt \& Gordon, 1985). As nearly as possible, the sequential method of scale development proposed by Jackson (1970, 1971) was used in the development of the questionnaire. A five point likert scale format is used, 
with higher scores representing greater endorsement of the item.

\section{Subjects}

Smokers and ex-smokers $(\underline{\mathrm{N}}=735)$ in Rhode Island and Houston, Texas responding to newspaper reports and advertisements completed questionnaires pertaining to their smoking behavior. A six month follow-up assessment included data on $99 \%$ of the participants $(\underline{N}=724)$. All 22 items of the questionnaire were completed by $89 \%(\underline{\mathrm{N}}=651)$ of the round 1 subjects and by $90 \%(\underline{\mathrm{N}}=648)$ of the round 2 subjects. Respondents ranged in age from 15 to 73 ( $\underline{\mathrm{M}}=$ $39.2, \underline{\mathrm{SD}}=12.2) ; 64 \%$ of the subjects were female, and $93 \%$ were white. Smokers in the sample $(\underline{N}=447)$ smoked an average of 26.5 cigarettes/day $(\underline{S D}=12.9)$, and had been smoking for an average of 19.6 years $(\underline{S D}=11.0)$. Round 2 demographics and smoking history characteristics were nearly identical to round 1 data.

\section{Procedure}

After volunteering for the study, informed consent was obtained from all participants. Subjects were mailed Relapse Ideology questionnaires along with other questionnaires pertaining to their smoking history and habits. Subjects were paid $\$ 4$ for completed questionnaires at both waves of data collection. No cessation interventions were introduced at any time during the course 
of the study.

Results

An initial principal components analysis with oblique rotation was conducted on the Rhode Island half of the round 1 sample $(\underline{N}=331)$ to eliminate poor items (e.g., items loading on more than one component, or failing to load on any component). The number of components to retain was determined using Velicer's (1976) MAP procedure and Horn's parallel analysis, both of which have been well-supported in simulation studies (Zwick \& Velicer, 1986). Both methods suggested a three component solution. Based on loading patterns and on theoretical (model) considerations, ten items were dropped from the original 22, leaving 12 items, with four items for each of the three components.

A second principal components analysis, again using an oblique rotation, was performed using these twelve items. The three factor solution accounted for $64 \%$ of the total shared variance. Component loadings for the twelve items are reported in Table 1 .

\section{Confirmation of the Factor structure}

Confirmation of the factor structure of the Relapse Ideology questionnnaire, and evaluation of the stability of its structure, was determined through confirmatory maximum likelihood factor analysis using the LISREL VI computer 
program (Jöreskog \& Sörbom, 1986). Such analyses provide rigorous statistical tests of the expected factor structure of an instrument.

Four alternative models were tested on the Texas half of the round 1 sample $(\underline{\mathrm{N}}=320)$ : 1) null model, 2) one factor model, 3) uncorrelated three-factor model, and 4) correlated three-factor model. The null model was not proposed as a serious model, but was employed as a baseline by which to assess other models. The one-factor model represented a test of the adequacy of a unidimensional model as an explanation of the underlying structure of the scale. The uncorrelated three-factor model was tested to allow comparison with the correlated three-factor model.

A comparison of the results on the four models is reported in Table 2. Chi-square results are significant for all models due to large sample size. The correlated threefactor model fit the data best in terms of goodness of fit indices $^{1}$, and furthermore, provided a significantly better fit than the uncorrelated three-factor model (Model (3) $\chi^{2}$ - Model (4) $x^{2}=224.44, \mathrm{~d} . \mathrm{f} .=3, \underline{\mathrm{p}}<.001$ ) and the one factor model (Model (2) $x^{2}-$ Model (4) $x^{2}=188.33$, d.f. = $2, \underline{\mathrm{p}}<.001)$.

Figure 1 shows the correlated three-factor model with item loadings and item error variances.

\section{Stability of Factor structure Across Samples}

In order to verify that the correlated three-factor model 
was invariant across different groups, two multiple sample analyses were conducted on round 2 data. The first analysis assessed the model on a sample from Rhode Island ( $\underline{N}=347$ ) with a sample from Texas $(\underline{N}=316)$. The second analysis compared women $(\underline{\mathrm{N}}=444)$ with men $(\underline{\mathrm{N}}=219)$.

For each of the three sample comparisons, six analyses were conducted, labeled Model A to Model F. Each model added progressively more restrictions to assess the comparability of the data across the samples on varying degrees of model restriction.

Model A was a test of the equality of covariance matrices for the two relevant samples. In order to justify using the combined samples for other analyses, it was important to verify that each pair of samples had similar covariance matrices.

Model B examined whether there was a common factor pattern across the two groups. The common factor pattern was the basic correlated three-factor model. Using psychometric terminology, this provided an assessment of a congeneric model with the same factor structure (i.e., the same pattern of loadings) but which allowed for different loadings, error variances, and correlations across groups.

Model $C$ examined the same basic model as Model B, except it restricted the factor loadings to be equal across groups. 
This was essentially a test that the model was tauequivalent across the two samples, which involves equal item loadings but permits item error variances and factor correlations to be unequal.

Model $D$ was the same as Model $C$ except it also restricted the item error variances to be equal across samples. This could be labeled as a parallel model which assumes equal loadings as well as equal error variances for all items across groups.

Model $E$ was the same as Model $D$ except that it allowed the error variances to be different while restricting the factor loadings and factor correlations to be equal across groups. This was similar in restrictiveness to Model D since both required two sets of parameters to be equal while allowing a third set to be free across the two groups.

Model $F$ combined restrictions from Models $D$ and $E$ by requiring that factor loadings, error variances, and the correlations among factors be equal across groups. This was the most restrictive model, which required every parameter estimate in the model to be equal across groups.

The results of the six models on the two multiple sample sets are given in Table 3. Summary statistics are given for the six model variants, including $x^{2}$, degrees of freedom, p- 
value, goodness-of-fit index (GFI), root mean square residual (RMS), chi-squared difference between the current model and Model $B$, and an indication of whether the difference test was significant.

In general, the results of the two multiple sample analyses suggest that the proposed three-factor correlated model is stable across independent samples. Results from both the Rhode Island versus Texas and the male versus female chi-square difference analyses were non-significant when comparing Models C through $F$ to Model B (same pattern) (Table 3). Thus, the correlated three factor model fit the data very well, even when very serious restrictions were placed on parameter estimates across the multiple samples.

\section{Stability of Factor structure over Time}

In order to assess structure invariance over time (6 months), the same correlated three component, 12 item solution was imposed on the round 2 data $(\underline{N}=663)$. The model fit the data very well, $\chi^{2}(51)=139.74, \mathrm{p}<.001$, GFI $=.97$, RMS $=.04, \operatorname{NFI}=.96, \operatorname{NNFI}=.96, \operatorname{IFI}(2)=.97$, $\mathrm{m}_{\mathrm{c}}=.99$, suggesting that the factor structure is stable over time.

\section{Psychometric Properties}

Further analyses were performed on both round 1 and round 
2 data in order to assess basic psychometric properties of the Relapse Ideology scales. Internal consistencies for the three scales were estimated using coefficient alpha (see Table 4) and are reasonably good across both rounds for four-item scales. Scale item means and standard deviations are also reported in Table 4. Correlations between factor scale scores and the Jackson (1967) social desirability scale, as well as between scale scores and various demographic characteristics, are shown in Table 5. All relationships were small, suggesting no important response distortions for these scales. Scale intercorrelations were moderate (see Table 4).

\section{External Validity}

In order to assess divergent validity of the three relapse ideology scales, subject scores were correlated with existing scales known to be relevant to cigarette smoking behavior. These scales included temptation and confidence (Velicer et al., 1989), and pros and cons of smoking (Velicer et al., 1985).

In general, the moral scale and the addictive behavior scale had little or no correlation with these other constructs (see Table 6), demonstrating the independence of the two relapse ideology scales with regard to other scales relevant to smoking behavior.

The disease scale, however, was found to have low to moderate correlations with these other scales (see Table 6). 
This was not surprising considering that the temptation and confidence constructs are indirect measures of cravings and habit strength, which are understandably related to endorsement of a disease model ideology.

In order to evaluate discriminant validity of the relapse ideology scales, several approaches were taken. First, a multivariate analysis of variance (MANOVA) was conducted using the three relapse ideology scales from the round 1 data set as dependent variables and light/heavy smoking status, defined by number of cigarettes per day (light $=1-$ 15 per day / heavy $=40$ or more per day), as the independent variable. Complete data from 153 light and heavy smokers were available for analysis. Scale item means and standard deviations are shown in Table 7 .

The multivariate main effect was significant: Wilks' Lambda $=.88, \underline{F}(3,149)=6.72, \underline{\mathrm{p}}<.001, \underline{\mathrm{R}}^{2}=.12$. Follow up univariate $\underline{F}$ tests revealed significant differences between light and heavy smokers on all three relapse ideology scales, with the moral, disease and addictive behavior scales accounting for seven, nine and eight percent of the variance $\left(\underline{\omega}^{2}\right)$ within the grouping variable, respectively (see Table 7 ). Heavy smokers had a higher mean endorsement of moral scale and disease scale items and a lower mean endorsement of addictive behavior scale items.

A follow-up discriminant classification analysis using the three relapse ideology scales was also performed. Group membership was correctly predicted for 53 of 82 heavy 
smokers (67\%) and 60 of 86 light smokers (67\%). The overall correct classification rate was $67 \%$.

A second approach used in assessing discriminant validity involved an attempt to evaluate whether or not individuals who progressed in terms of stage of change (Prochaska \& Diclemente, 1983) responded differentially on the relapse ideology scales (round 1) when contrasted with those who remained stable or moved in a negative direction along the stages of change continuum across the two rounds of data collection. A MANOVA was performed using a grouping variable which differentiated between those who failed to show positive progression with regard to stage of change and those subjects that did show positive progression across the two rounds. Complete data was available for 608 subjects. scale item means and standard deviations are shown in Table 8 .

The multivariate main effect was significant: Wilks' Lambda $=.95$, approximate $\underline{F}(3,604)=10.0, \underline{\mathrm{p}}<.001, \quad \underline{\mathrm{R}}^{2}=$ .05 . Follow up univariate $\underline{E}$ tests revealed significant mean differences between stage progressors and non-progressors on two of the three relapse ideology scales, with the disease and addictive behavior scales each accounting for one percent of the variance $\left(\underline{\omega}^{2}\right)$ within the grouping variable (see Table 8 ). Subjects who demonstrated progress through the stages of change over the two rounds had a higher mean endorsement of disease scale and addictive behavior scale items. 
A follow up discriminant classification analysis was also performed. Group membership was correctly predicted for 253 of 455 non-progressors (56\%) and 93 of 153 progressors (61\%). The overall correct classification rate was $57 \%$.

This relatively poor rate of successful classification revealed in the above analysis prompted a third approach. An attempt was made to determine whether or not the relapse ideology scales could add to the predictive power of constructs previously determined to be good predictors of smoking status. This approach was consistent with the view that relapse ideology is only one aspect of a smoker's profile.

A stepwise discriminant classification analysis was performed, using the same grouping variable described above which differentiated between those who failed to show positive progression with regard to stage of change and those subjects that did show positive progression. Variables which were allowed to enter in the prediction equation included scores from the three relapse ideology scales, as well as scale scores for the ten processes of change (Prochaska et al., 1988).

The stepwise analysis yielded a discriminant function which included four of the ten processes and two of the relapse ideology scales (the disease and addictive behavior scales). Using these six variables, a $66 \%$ classification rate was achieved. Group membership was correctly predicted for 262 of 311 non-progressors (66\%) and 136 of 230 
progressors (66\%). The discriminant function accounted for $10.6 \%$ of the variance within the grouping variable. Standardized canonical weights are found in Table 9. The fact that these two scales added significantly to the predictive ability of the processes served as further evidence of a relationship between movement through the stages of change and relapse ideology .

\section{Discussion}

This study resulted in a short, 12-item questionnaire that measures three important constructs relating to how individuals perceive smoking relapse. The three scales possessed adequate internal consistency and the factor structure of the questionnaire was stable across time and across various subgroups of the study population. The three constructs are consistent with the moral, disease, and addictive behavior models of addiction presented by Marlatt and Gordon (1985).

Due to the fact that this was a naturalistic study (i.e., no cessation intervention implemented), the extremely limited number of subjects experiencing a relapse episode between assessments prohibited analyses posing relapse status as a criterion for external validity. This is unfortunate in that relapse status would have been an ideal criterion variable. As an alternative, the reported analyses were designed to assess external validity. 
Divergent validity of the three scales was adequate, suggesting that they are independent of a number of existing scales related to smoking behavior. Attempts to establish discriminant validity of these scales yielded less easily interpretable results. The relapse ideology scales were shown to have significant relationships with both light/heavy smoking status, as well as with a variable representing movement along the stages of change continuum. However, while these relationships were statistically significant, the relapse ideology scales were only marginally successful with regard to predicting light/heavy smoking status and stage movement via a discriminant classification analysis. While these results suggest less than ideal measurement properties, they are not inconsistent with the perspective that relapse ideology is only one aspect of a smoker's profile, representing only a single piece of the information potentially important with regard to understanding and predicting smoking behavior.

Futhermore, the analyses performed in assessing discriminant validity have not considered the scales in terms of subject profiles of relapse ideology. Cluster analyses of the scales will provide an initial attempt to construct such profiles. Because the analyses which will be performed once these profiles have been established require viewing this data in an entirely different manner (i.e., focusing on types of people, rather than on relationships between scale scores) it is impossible to predict their 
results. The potential for finding further evidence of external validity, however, is quite good given the established measurement properties of the relapse ideology scales.

The development of the Relapse Ideology questionnaire has important implications with regard to future smoking cessation intervention efforts. As Brickman (1982) points out, "many of the problems characterizing relationships between help givers and help recipients arise from the fact that the two parties are applying models that are out of phase with one another" (pg. 375). In other words, an individual who endorses the disease model may fail miserably within a cognitive behavioral program which neglects to address the fact that this individual does not initially hold himself responsible for taking steps to change his addictive behavior.

Consistent with this view, assessment of individual relapse ideologies may prove to be an important component of screening procedures associated with smoking cessation treatment and research efforts. Profile screening of this sort could be valuable if individual smoker profiles could be matched to the specific treatment approach with greatest impact at the lowest cost (Brownell, Marlatt, et al., 1986, p. 773). Tailoring of interventions which interactively address the smoker's attitudes and behavior has shown preliminary success in helping people quit smoking (Prochaska \& Velicer, 1989). Knowledge of relapse ideology 
profiles may prove to be a significant contribution to this treatment strategy, as well.

Finally, from a theoretical perspective, the ability to reliably measure relapse ideology may also contribute to our understanding of how and why some people are able to quit smoking through their own self-help efforts, while others are not.

\section{Future Work}

Refinement of the reported measurement model for relapse ideology is currently under way. The next step in this process involves cluster analyses designed to establish relapse ideology profiles, the purpose of which has been discussed briefly above.

Replication of this study in order to provide further confirmation of the factor structure of the Relapse Ideology questionnaire would also be a valuable undertaking. However, prior to any further collection of additional data the possibility of further item revision and creation of new items should be considered.

The current revised four-item moral and addictive behavior scales are particularly strong, both in terms of quantitative measurement properties, as well as with regard to their congruence with the theoretical constructs. (Figure 1 contains all items and item loadings from round 1, Texas sample, confirmatory model.)

The four items from the revised moral scale all involve 
self-attributions which imply that a personal failing or weakness is related to smoking relapse. The idea that the individual is wholly responsible for a relapse episode is clearly consistent with the moral model, both in terms of Brickman's (1982) conceptualization, as well as Marlatt and Gordon's (1985).

The four items which make up the revised addictive behavior scale all focus on the issues of whether one "slip" leads to an inevitable relapse or whether "controlled" smoking can lead to a successful quit attempt. In other words, these items are concerned with whether or not one can recover from a slip, or a planned return to smoking, and subsequently successfully quit smoking. These four items effectively assess endorsement of the addictive behavior model, especially as operationalized in Marlatt and Gordon's Relapse Prevention model (1985).

The disease scale, however, is less strong and could benefit from additional or different items. Although the current scale is adequate in terms of its psychometric properties, the face validity of these items is suspect. The item with the highest loading in the confirmatory model deals with the issue of an inability to "resist" a second or third cigarette after one slip. This suggests the concept of a lack of control over relapse on the part of the smoker, implying a physiological component, which is consistent with the theoretical construct. In this sense this item may be a good "marker" for this scale. The three remaining items, 
however, are difficult to distinguish in terms of face validity from items belonging to the addictive behavior scale. They all involve whether or not one can recover from a single slip, but do not imply a physiological component. The disease items do consistently emphasize an "abstinent versus smoking" perspective. However, the addictive behavior items, in many respects, are very similar to the these three items, all emphasizing the feasibility of "controlled" smoking after having quit.

In consideration of this problem with face validity, a previously unreported analysis was conducted which merged these two scales (disease and addictive behavior) into one eight item scale. The results indicated that the original factor structure fit the data significantly better (Model (2 Factor) $\chi^{2}$ - Model ( 3 Factor) $\chi^{2}=129.37$, d.f. $=2, \underline{p}<$ .001), which was encouraging. However, it is hard to overlook that it is difficult to differentiate between items from the disease and addictive behavior scales.

An accurate conceptualization of the disease construct would ideally involve the concept of a physiological addiction, or irresistible cravings as being at the root of any relapse episode, be it the first "slip" or a long-term return to pre-cessation smoking rate. While the issue of the possibility of "controlled" smoking versus complete abstinence seems to be at the heart of the addictive behavior model, a theoretically consistent disease model scale should focus clearly on the issue of control over any 
return to smoking, primarily the first slip. The disease model does suggest that a single slip generally leads to a return to "the disease state," implying pre-cessation smoking rates are likely to re*^T. However, this is a secondary aspect of the model which is vital in terms of treatment considerations, but may not be important to emphasize when attempting to measure a disease model relapse ideology .

It is recommended that any future study of relapse ideology involving further data collection include the creation and analyses of additional items which may ultimately strengthen the disease scale. These items would ideally more directly target the concept of a physiological addiction, implying a lack of control, and therefore, lack of responsibility for relapse on the part of the smoker. Examples of such items include; 1) If I smoked one cigarette after quitting it would be primarily due to an irresistible need to smoke; 2) Whether or not I am able continue not smoking after having quit is more a matter of biology than anything else; 3) If I smoked one cigarette after quitting, it would be primarily due to an irresistible craving.

These items, or perhaps similar items, would hopefully prove to be more highly correlated with the strongest item (item with highest loading in confirmatory model) in the existing scale, thus increasing the face validity of the disease scale. 
References

Baer, J.S., Kamarck, T., Lichtenstein, E., \& Ransom, Jr., c.C. (1989). Prediction of smoking relapse: Analyses of temptations and transgressions after initial cessation. Journal of consulting and Clinical Psychology, 57, 623627.

Bellis, J.M., Rossi, J.S., Diclemente, C.C., \& Prochaska, J.o. (1989). A relapse ideology measurement model: Structural invariance over time and samples. Paper presented at the 97 th annual convention of the American Psychological Association, New Orleans, IA.

Bentler, P.M., \& Bonett, D.G. (1980). Significance tests and goodness of fit in the analysis of covariance structures. Psychological Bulletin, 88, 588-606.

Brickman, P., Rabinowitz, V.C., Karuza, Jr., J., coates, D. , Cohn, E., \& Kidder,L. (1982). Models of helping and coping. American Psychologist, 37, 368-384.

Brownell, K.D., Glynn, T.J., Glasgow, R., Lando, H. , Rand, C., Gottleib, A., \& Pinney, J.M. (1986). Task force 5: Interventions to prevent relapse. Health Psychology, 5(Suppl.), 53-68.

Brownell, K.D., Marlatt, G.A., Lichtenstein, E., \& Wilson, 
G.T. (1986). Understanding and preventing Relapse. American Psychologist, 41, 765-782.

Hunt, W.A., \& Belaspec, D.A. (1974). An evaluation of current methods of modifying smoking behavior. Journal of Clinical Psychology, 30, 431-438.

Jackson, D.N. (1967). Personality Research Form. Port Huron, MI: Research Psychologists Press.

Jackson, D.N. (1970). A sequential system for personality scale development. In C.D. Spielberger (Ed.), current topics in clinical and community psychology (Vol.2, pp. 61-96). New York: Academic Press.

Jackson, D.N. (1971). The dynamics of structured personality tests: 1971. Psychological Review, 78, 229-248.

Jöreskog, K.C., \& Sörbom, D. (1986) . LISREL VI. Morresville, IN: Scientific Software.

Marlatt, G. A., \& Gordon, J.R. (1985). Relapse prevention: Maintenance strategies in the treatment of addictive behaviors. New York: Guilford Press.

McDonald, R. (1989). An index of goodness-of-fit based on noncentrality. Journal of Classification, 6, 97-103. 
Mulaik, S.A., James, L.R., Van Alstine, J., Bennett, N., Lind, S., \& Stilwell, C.D. (1988). Evaluation of goodness-of-fit indices for structural equation models. Psychological Bulletin, 105, 430-445.

Niaura, R.S., Rohsenow, D.J., Binkoff, J.A., Monti, P.M., Pedraza, M., \& Abrams, D.B. (1988). Relevance of cue reactivity to understanding alcohol and smoking relapse. Journal of Abnormal Psychology, 97, 133-152.

Prochaska, J.O., \& Diclemente, C.C. (1983). Stages and processes of self-change of smoking: Toward an integrated model of change. Journal of consulting and Clinical Psychology, 51, 390-395.

Prochaska, J.o., \& Diclemente, C.C. (1986). Toward a comprehensive model of change. In W.R. Miller \& N. Hether (Eds.), Treating addictive behaviors, (pp. 3-27). New York: Plenum Press.

Prochaska, J.O., Velicer, W.F. (1989). Self-help models and materials for smoking cessation. Proposal submitted for consideration to the National Cancer Institute for continuation of grant CA27821.

Prochaska, J.o., Velicer, W.F., Diclemente, C.C., \& Fava, J. (1988). Measuring processes of change: Applications 
to the cessation of smoking. Journal of Consulting and Clinical Psychology, 56, 520-528.

Prochaska, J.o., Velicer, W.F., Diclemente, C.C., Guadagnoli, E., \& Rossi, J.S., (in press). Patterns of change: Dynamic topology applied to smoking cessation. Multivariate Behavioral Research.

Velicer, W.F. (1976). Determining the number of components from the matrix of partial correlations. Psychometrika, 41, $321-327$.

Velicer, W.F., Diclemente, C.C., Prochaska, J.o., Brandenburg, N. (1985). Decisional balance measure for assessing and predicting smoking status. Journal of Personality and Social Psychology, 48, 1279-1289.

Velicer, W.F., Diclemente, C.C., Rossi, J.S., \& Prochaska, J.O. (1989). Relapse Situations and self-efficacy: An integrative model. Addictive Behaviors, (in press).

Wilcox, N.S., Prochaska, J.O., Velicer, W.F., \& Diclemente, C.C. (1980). Subject characteristics as predictors of self-change in smoking. Addictive Behaviors, 10, 407-412. 
Zwick, W.R., \& Velicer, W.F. (1986). A comparison of five rules for determining the number of components to retain. Psychological Bulletin, 99, 432-442. 


\section{Footnotes}

1 Given there remains disagreement regarding the most appropriate index of model fit, several of the most well recognized indices have been reported in Table 2 . These include; goodness-of-fit index (GFI) (Jöreskog \& sörbom, 1986); normed fit index (NFI) (Bentler \& Bonett, 1980); nonnormed fit index (Bentler \& Bonett, 1980); and, McDonald's noncentrality index $\left(m_{c}\right)$ (McDonald, 1989).

2 In response to preliminary presentation of the measurement properties of the Relapse Ideology questionnaire, (Bellis, Rossi, Diclemente, \& Prochaska, 1989), Susan Curry (personal communication, October 23, 1989) has suggested that the addictive behavior scale items may be somewhat limited with regard to assessment of the construct. She proposed that this scale might benefit from items emphasizing the importance of coping skills. creation and testing of such items should certainly be considered prior to any further data collection using the Relapse Ideology questionnaire. 
Table 1

Principa1 Component Loadings: 12 Item, 3 Factor Solution

Round 1 - Rhode Island Sample $(\underline{N}=331)$

ITEM

LOADING

Component 1 - Addictive Behavior

8. It is alright to smoke one or two cigarettes after you have quit.

10. It is possible to smoke only on special occassions.

11. Once the smoking habit is really conquered, an occassional cigarette or two would be okay.

12. People who allow themselves a cigarette or two after they have quit have the best chance of eventually staying off cigarettes forever.

Component 2 - Moral

4. If I smoked one cigarette after I had quit I would consider myself a fallure. .789

16. If I smoked one cigarette after I had quit I would consider myself a weak person.

18. If I smoked one cigaratte after I had quit I would consider myself a normal person.

22. I would feel very guilty if I smoked a cigarette after I quit.

\section{Component 3 - Disease}

2. People who have quit will inevitably return to smoking after one slip.

3. I could probably smoke a cigarette or two after I quit and still not go back to smoking.

15. If I smoked one cigarette after quitting, I would be unable to resist a second or a third.

19. If after quitting I slipped and had one cigarette, I would give up trying to quit. 


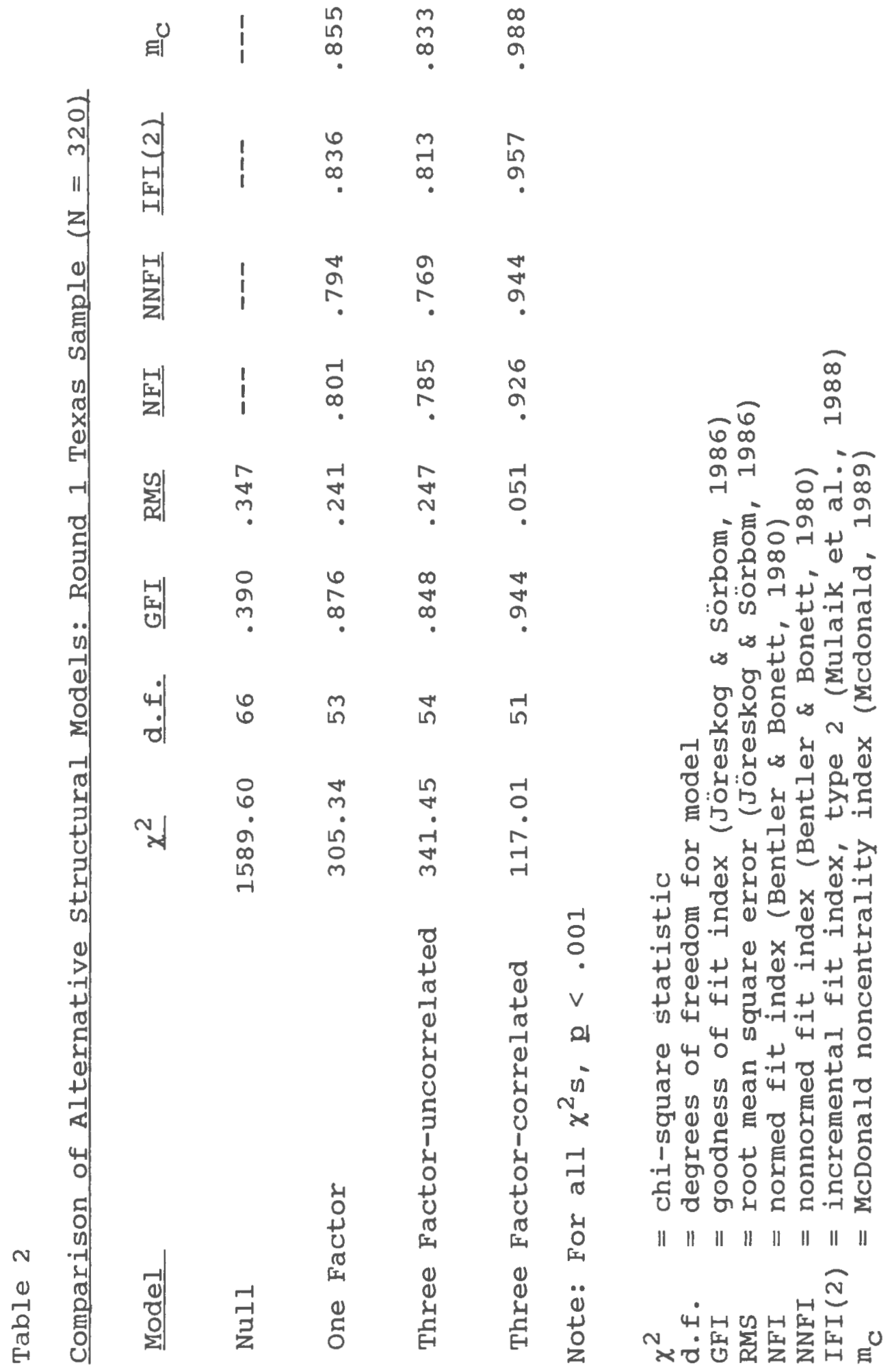


Table 3

Multiple Sample Analyses:

Comparison of Male and Female Samples - Round $2(\mathrm{~N}=663)$

\begin{tabular}{llrrrrr} 
Model & Chi-Sq & df & p & GFI & RMS & $\chi^{2} / \mathrm{df} / \mathrm{sig}$ \\
\hline A & 100.76 & 78 & .043 & .953 & .053 & $\ldots$ \\
B & 197.94 & 102 & $<.001$ & .947 & .042 & $-\ldots$ \\
C & 212.43 & 114 & $<.001$ & .941 & .066 & $14.49 / 12 / N S$ \\
D & 229.10 & 126 & $<.001$ & .934 & .061 & $31.16 / 24 / N S$ \\
E & 217.95 & 117 & $<.001$ & .939 & .072 & $20.01 / 15 / N S$ \\
F & 234.95 & 129 & $<.001$ & .932 & .068 & $37.01 / 27 / N S$
\end{tabular}

Comparison of Rhode Is land and Texas Samples - Round $2(N=663)$

\begin{tabular}{lrrrrrr} 
Model & Chi-Sq & df & p & GFI & RMS & $\chi^{2} / \mathrm{df} / \mathrm{sig}$ \\
\hline A & 79.98 & 78 & .448 & .982 & .030 &.- \\
B & 194.50 & 102 & $<.001$ & .959 & .041 &.- \\
C & 205.00 & 114 & $<.001$ & .957 & .046 & $10.50 / 12 / \mathrm{NS}$ \\
D & 216.82 & 126 & $<.001$ & .955 & .044 & $22.32 / 24 / \mathrm{NS}$ \\
E & 207.53 & 117 & $<.001$ & .957 & .048 & $13.03 / 15 / \mathrm{NS}$ \\
F & 220.26 & 129 & $<.001$ & .954 & .048 & $25.76 / 27 / \mathrm{NS}$
\end{tabular}

Note:

GFI = Jöreskog \& Sörbom goodness-of-fit index

RMS $=$ root mean square residual

$\chi^{2} / \mathrm{df} / \mathrm{sig}=$ Chi-squared difference test of current model minus Model $B /$ difference in degrees of freedom/significance of test where NS = not significant and $*=p<.05$ 
Table 4

Scale Statistics and Correlations: Round 1 Sample

Scale

Mean SD Alpha

Scale Correlations

Moral

3.02

$0.93 \quad 0.80$

1.00

Disease

2.99

0.84

0.73

$.47 \quad 1.00$

Addictive Behavior

2.11

0.87

0.85

$-.54$

$-.45 \quad 1.00$

Note: $\underline{N}^{\prime} s=671$ to $675 ;$ for a11 correlations, $\underline{p}<.001$.

Scale Statistics and Correlations: Round 2 Sample

\begin{tabular}{lcccccr} 
Scale & Mean & SD & Alpha & \multicolumn{2}{c}{ Scale Correlations } \\
\hline Moral & 2.96 & 0.93 & 0.80 & 1.00 & \\
Disease & 2.99 & 0.89 & 0.74 & .53 & 1.00 & \\
Addictive Behavior & 2.12 & 0.90 & 0.84 & -.52 & -.53 & 1.00
\end{tabular}

Note: $\underline{N}^{\prime} \mathrm{s}=666$ to 669 ; for all correlations, $\underline{p}<.001$. 
Table 5

Scale Correlations with Social Desirability and Demographic Variables:

Round 1 Sample

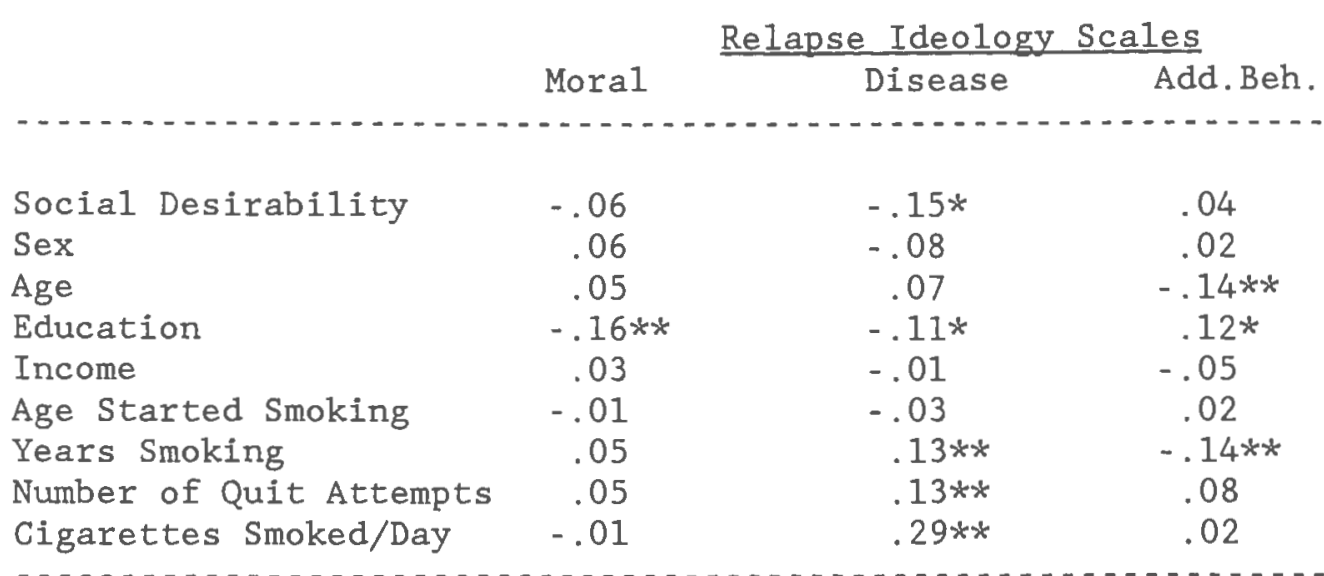

Note: Social desirability scale administered to a subsample of subjects $(\underline{N}=195)$. $\underline{N}^{\prime}$ 's for other correlation coefficients range from 602 to 675 .

$* \mathrm{p}<.01 \quad * * \mathrm{p}<.001$

Round 2 Sample

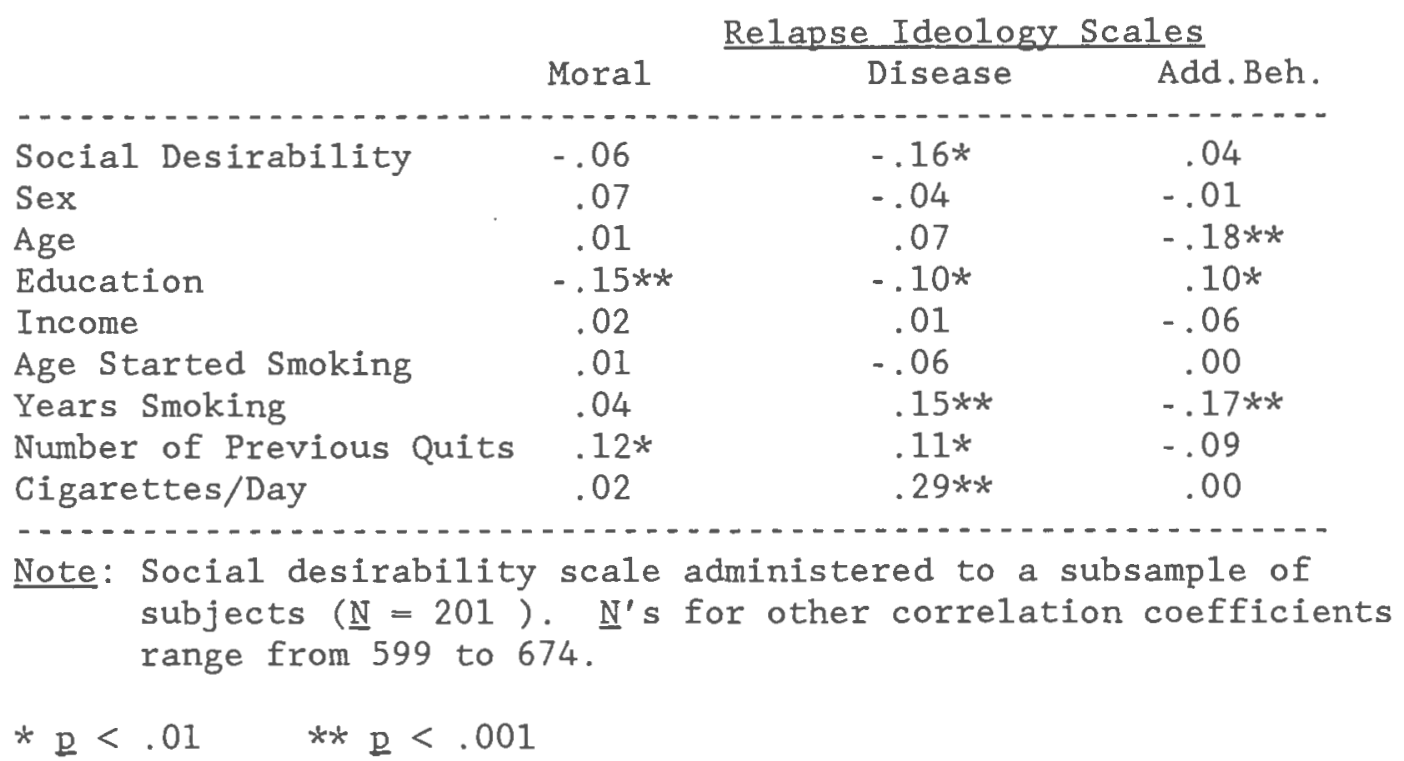


Table 6

Correlations With Other Smoking Scales: Round 1 Sample

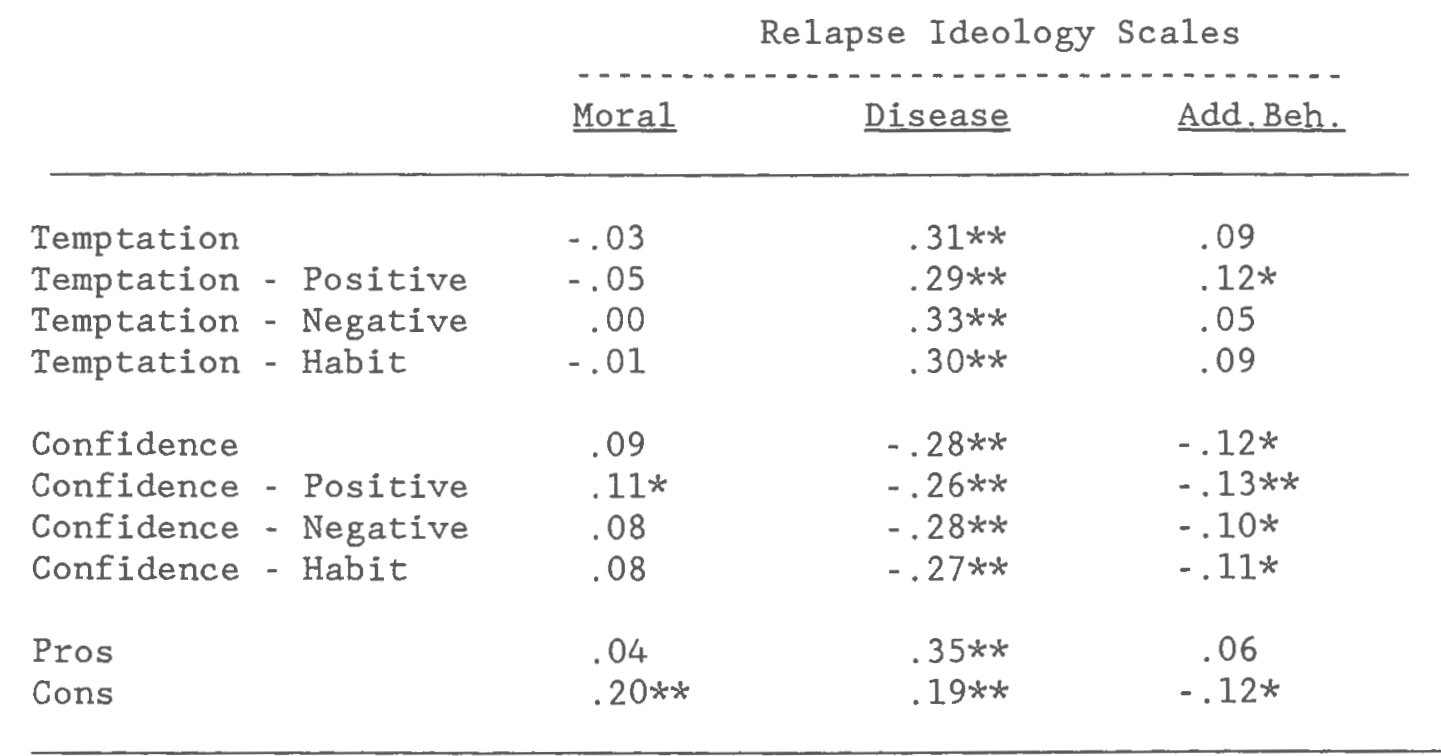

Note: N's for correlation coefficients range from 601 to 675 .

$* \mathrm{P}<.01 \quad * * \mathrm{P}<.001$ 
Table 7

Relapse Ideology Scale Item Means, Standard Deviations and ANOVA Results:

Light and Heavy Smokers

Mean and Standard Deviation

\begin{tabular}{|c|c|}
\hline Scale (Round 1) & Heavy \\
\hline
\end{tabular}

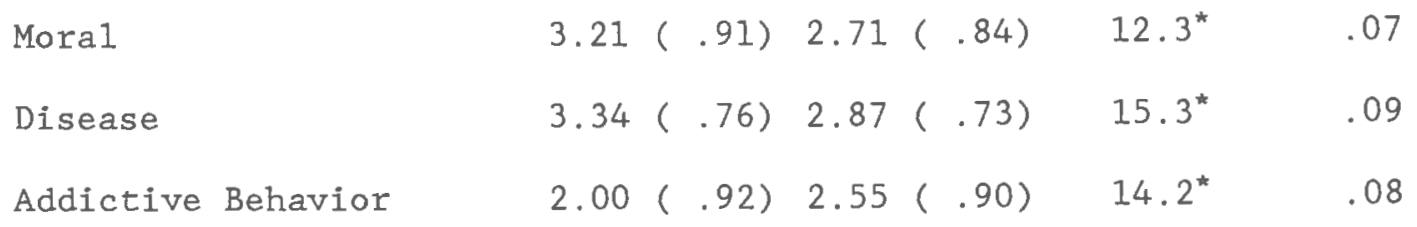

$* \mathrm{p}<.001$ 
Table 8

Relapse Ideology Scale Item Means, Standard Deviations and ANOVA Results:

Non-progressors vs. Progressors

Mean and Standard Deviation

Scale (Round 1) $\quad$ Non-prog. Progressors $\quad \underline{\text { (1.606) }} \underline{\omega}^{2}$

$\begin{array}{lllll}\text { Moral } & 3.03(.94) & 3.01(.86) & 0.02 & \ldots \\ \text { Disease } & 2.91(.89) & 3.15(.73) & 8.30^{\star} & .01 \\ \text { Addictive Behavior } & 2.07(.85) & 2.28(.91) & 7.30^{*} & .01\end{array}$

$\star \mathrm{p}<.01$ 
Table 9

Standardized Discriminant Weights:

Non-progressors vs. Progressors Analysis

Unstandardized Standardized

Discriminant Discriminant

Weights

Processes of Change

Counter Conditioning

Reinforcement

12

$-.13$

$-.13$

Self-reevaluation

Consciousness

Raising

Relapse Ideology

Scales

Disease Scale

Addictive Behavior

Scale

Constant
$-.15$

$-.18$

3.34
Structure

Coefficients

$.59 \quad .37$

$.37 \quad .09$

$-.44 \quad-.40$

$-.58 \quad-.38$

$-.52 \quad-.36$

$-.62-.27$ 


\section{Figure 1}

Correlated Three-factor Model with Item Loadings and Item Error Variances

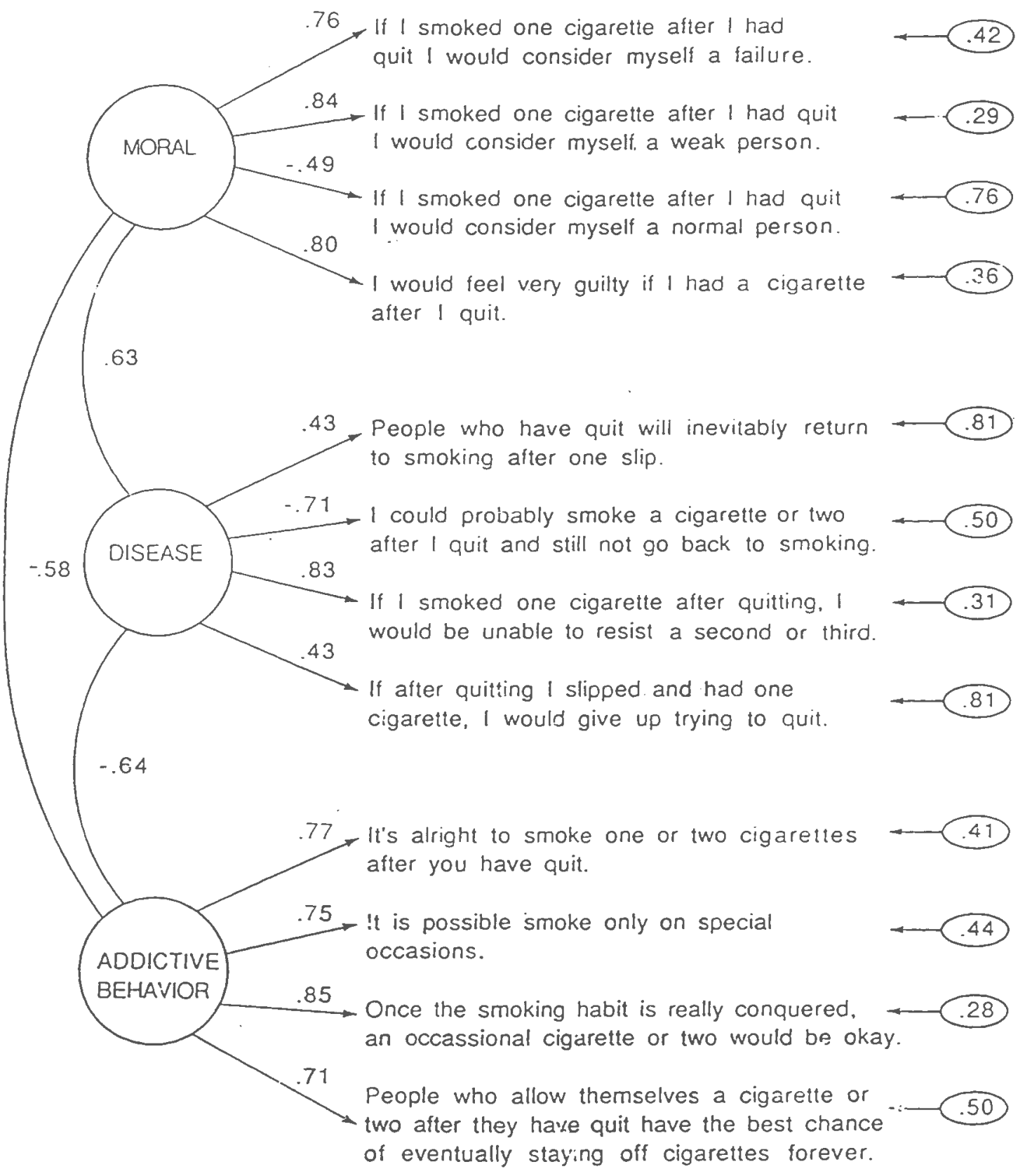




\section{Bibliography}

Baer, J.S., Kamarck, T., Lichtenstein, E., \& Ransom, Jr., C.C. (1989). Prediction of smoking relapse: Analyses of temptations and transgressions after initial cessation. Journal of Consulting and Clinical Psychology, 57, 623627.

Bellis, J.M., Rossi, J.S., Diclemente, C.C., \& Prochaska, J.O. (1989). A relapse ideology measurement model: Structural invariance over time and samples. Paper presented at the 97 th annual convention of the American Psychological Association, New orleans, LA.

Bentler, P.M., \& Bonett, D.G. (1980). Significance tests and goodness of fit in the analysis of covariance structures. Psychological Bulletin, 88, 588-606.

Brickman, P., Rabinowitz, V.C., Karuza, Jr., J., Coates, D., Cohn, E., \& Kidder,L. (1982). Models of helping and coping. American Psychologist, 37, 368-384.

Brownell, K.D., Glynn, T.J., Glasgow, R., Lando, H., Rand, C. Gottleib, A., \& Pinney, J.M. (1986). Task force 5: Interventions to prevent relapse. Health Psychology, 5(Suppl.), 53-68.

Brownell, K.D., Marlatt, G.A., Lichtenstein, E., \& Wilson, 
G.T. (1986). Understanding and preventing Relapse. American Psychologist, 41, 765-782.

Hunt, W.A., \& Belaspec, D.A. (1974). An evaluation of current methods of modifying smoking behavior. Journal of Clinical Psychology, 30, 431-438.

Jackson, D.N. (1967). Personality Research Form. Port Huron, MI: Research Psychologists Press.

Jackson, D.N. (1970). A sequential system for personality scale development. In C.D. Spielberger (Ed.), current topics in clinical and community psychology (Vol.2, pp. 61-96). New York: Academic Press.

Jackson, D.N. (1971). The dynamics of structured personality tests: 1971. Psychological Review, 78, 229-248.

Jöreskog, K.C., \& Sörbom, D. (1986) . LISREL VI. Morresville, IN: scientific software.

Marlatt, G. A., \& Gordon, J.R. (1985). Relapse prevention: Maintenance strategies in the treatment of addictive behaviors. New York: Guilford Press.

McDonald, R. (1989). An index of goodness-of-fit based on noncentrality. Journal of Classification, ㅁ, 97-103. 
Mulaik, S.A., James, L.R., Van Alstine, J., Bennett, N., Lind, S., \& Stilwell, C.D. (1988). Evaluation of goodness-of-fit indices for structural equation models. Psychological Bulletin, 105, 430-445.

Niaura, R.S., Rohsenow, D.J., Binkoff, J.A., Monti, P.M., Pedraza, M., \& Abrams, D.B. (1988). Relevance of cue reactivity to understanding alcohol and smoking relapse. Journal of Abnormal Psychology, 97, 133-152.

Prochaska, J.O., \& DiClemente, C.C. (1983). Stages and processes of self-change of smoking: Toward an integrated model of change. Journal of consulting and Clinical Psychology, 51, 390-395.

Prochaska, J.O., \& Diclemente, C.C. (1986). Toward a comprehensive model of change. In W.R. Miller \& N. Hether (Eds.), Treating addictive behaviors, (pp. 3-27). New York: Plenum Press.

Prochaska, J.O., Velicer, W.F. (1989). Self-help models and materials for smoking cessation. Proposal submitted for consideration to the National Cancer Institute for continuation of grant CA27821.

Prochaska, J.O., Velicer, W.F., Diclemente, C.C., \& Fava, J. (1988). Measuring processes of change: Applications 
to the cessation of smoking. Journal of Consulting and Clinical Psychology, 56, 520-528.

Prochaska, J.O., Velicer, W.F., Diclemente, C.C., Guadagnoli, E., \& Rossi, J.S., (in press). Patterns of change: Dynamic topology applied to smoking cessation. Multivariate Behavioral Research.

Velicer, W.F. (1976). Determining the number of components from the matrix of partial correlations. Psychometrika, 41, $321-327$.

Velicer, W.F., Diclemente, C.C., Prochaska, J.O., Brandenburg, N. (1985). Decisional balance measure for assessing and predicting smoking status. Journal of Personality and Social Psychology, 48, 1279-1289.

Velicer, W.F., Diclemente, C.C., Rossi, J.S., \& Prochaska, J.0. (1989). Relapse Situations and self-efficacy: An integrative model. Addictive Behaviors, (in press).

Wilcox, N.S., Prochaska, J.O., Velicer, W.F., \& Diclemente, C.C. (1980). Subject characteristics as predictors of self-change in smoking. Addictive Behaviors, 10, 407-412. 
Zwick, W.R., \& Velicer, W.F. (1986). A comparison of five rules for determining the number of components to retain. Psychological Bulletin, 99, 432-442. 